\title{
Two different begomovirus species are associated with yellow vein mosaic disease of okra in Sri Lanka.
}

Article

Accepted Version

Jeyaseelan, T. C. ORCID: https://orcid.org/0000-0002-7620112X, De Costa, D. M. and Shaw, M. W. (2021) Two different begomovirus species are associated with yellow vein mosaic disease of okra in Sri Lanka. Molecular Biology Reports, 48 (2). pp. 1383-1391. ISSN 1573-4978 doi:

https://doi.org/10.1007/s11033-021-06213-3 Available at https://centaur.reading.ac.uk/96683/

It is advisable to refer to the publisher's version if you intend to cite from the work. See Guidance on citing.

To link to this article DOI: http://dx.doi.org/10.1007/s11033-021-06213-3

Publisher: Springer

All outputs in CentAUR are protected by Intellectual Property Rights law, including copyright law. Copyright and IPR is retained by the creators or other copyright holders. Terms and conditions for use of this material are defined in the End User Agreement. 


\section{CentAUR}

Central Archive at the University of Reading

Reading's research outputs online 


\section{Title Page}

Title:

Two different begomovirus species are associated with yellow vein mosaic disease of okra in Sri Lanka.

\section{Authors:}

T.C.Jeyaseelan ${ }^{1,4}$, D.M. De Costa ${ }^{2,4}$, M.W.Shaw ${ }^{3}$

Affiliations:

${ }^{1}$ Department of Botany, Faculty of Science, University of Jaffna, Jaffna, Sri Lanka

${ }^{2}$ Department of Agricultural Biology, Faculty of Agriculture, University of Peradeniya, Peradeniya, Sri Lanka

${ }^{3}$ School of Agriculture, Policy and Development, University of Reading, Reading, United Kingdom

${ }^{4}$ Plant Protection Board of Study, Postgraduate Institute of Agriculture, University of Peradeniya, Peradeniya, Sri Lanka

\section{Corresponding author:}

Correspondence to T.C.Jeyaseelan

E-mail address: cjtharmila@univ.jfn.ac.lk ; siva.tharmi3@gmail.com

\section{Acknowledgements:}

The authors are grateful to Dr. George Gibbings and Dr. Ihsan Ullah (Molecular Genetics Laboratory, School of Agriculture, Policy and Development, University of Reading, UK) for technical assistance. The works in Sri Lanka was supported by University Grants Commission, Government of Sri Lanka under the project: UGC/DRIC/PG/2015(ii)/JFN/01. 


\begin{abstract}
Background: Yellow vein mosaic disease is the major biotic constraint of okra cultivation in Sri Lanka. Identification and detailed molecular characterization of associated pathogen is needed for effective disease management.
\end{abstract}

Methods and Results: The genome of the begomovirus and betasatellite were amplified in symptomatic plant samples using specific degenerate primers. DNA-A genome of twelve isolates representing different locations in Sri Lanka were cloned, sequenced and deposited in GenBank database (Accession No- KX698087- KX698092 and MH455207- MH455212). Size of the complete nucleotide sequences ranged from 2735 bp to 2786 bp. The genome organization showed characteristics of begomoviruses. The pairwise sequence identity revealed the association of two different begomovirus species. Five of the isolates showed $>91 \%$ of sequences identity with Bhendi yellow vein mosaic virus, and the rest of the seven isolates were around $92 \%$ of identity with Okra enation leaf curl virus. This is further supported by phylogenetic analysis where both of these group of isolates were in different cluster. Recombination analysis showed the presence of recombinant fragments in the virus isolates associated with okra yellow vein mosaic disease (OYVMD) in Sri Lanka. Attempts to amplify DNA- B were failed in any of the samples tested. However, both type of the begomovirus species associated with betasatellite species, Bhendi yellow vein mosaic betasatellite.

Conclusions: The present study has revealed the association of two distinct monopartite begomovirus species, Bhendi yellow vein mosaic virus or Okra enation leaf curl virus, with OYVMD in Sri Lanka.

Key words: Begomoviruses, Betasatellites, Okra, Okra yellow vein mosaic disease, Phylogenetic relationship. 


\section{Declaration}

Funding: The works in Sri Lanka was supported by University Grants Commission, Government of Sri Lanka under the project: UGC/DRIC/PG/2015(ii)/JFN/01.

Conflicts of interest: Authors declare that they have no conflict of interest.

Ethics approval: Not applicable

Consent to participate: Not applicable

Consent for publication: Not applicable

Availability of data and material: Not applicable

Code availability: Not applicable

\section{Authors' contribution:}

This work was carried out in collaboration between all authors. T.C.Jeyaseelan contributed designing the experiments, carried out all experiments and wrote the first draft of the manuscript. D.M. De Costa designed and supervised the experimental process. M.W.Shaw performed data analysis and supervised the experiments. . All authors read and approved the final manuscript 


\section{Introduction}

Begomovirus is the most important genus within the family Geminiviridae. The members of this genus are transmitted by whitefly, Bemisia tabaci. The begomoviruses infect a range of crop plants such as tomato, papaya, radish, okra, mungbean, pigeon pea, soybean, chilli, cotton, tobacco etc. [1-5]. In general, begomoviruses can have either monopartite or bipartite genomes. Bipartite begomovirus genomes comprise of two ssDNA molecules (2.8 kb each), referred to as DNA-A and DNA-B. The DNA-A genome contains either five or six open reading frames (ORFs). The coat protein $(\mathrm{CP})$ and pre-coat protein (Pre-CP) are coded in the viral sense strand, and the complementary sense strand code for replication-associated protein (Rep), transcriptional activator protein (TrAP), replication enhancer (Ren) and AC4 protein. The DNA-B genome has ORFs BV1 and BC1; they code for a nuclear shuttle protein (NSP) and movement protein (MP), respectively. The noncoding intergenic region (IR, approximately $500 \mathrm{bp}$ ) contains the origin of replication, where the viral Rep protein binds for initiating rolling circle replication. A part of this region is conserved between the two DNA components of bipartite begomoviruses. In monopartite begomovirus, the genome consists DNA-A component only, and the virus is usually associated with additional ssDNA molecules known as satellites [2].

The betasatellite is a circular, single-stranded DNA molecule varies from $1.3 \mathrm{~kb}$ to $1.5 \mathrm{~kb}$. Betasatellite molecules have a single conserved ORF which encode $\beta C 1$, whereas, some recent reports suggest it also encode another ORF, called $\beta$ V1 [3]. Even though the betasatellite molecules are considered as an associated DNA particle in begomovirus complex, it is the predominant factor to determine symptom development in host plants [4]. The alphasatellites encode their own replication-associated protein and depend on the helper virus for encapsidation, movement and transcription [5]. The alphasatellites attenuates the disease symptoms and maintained the gathering of betasatellite at low level [6].

Okra (Abelmoschus esculentus (L.) Moench) is one of the major vegetable crops in Sri Lanka and is cultivated in diverse climatic conditions, namely, wet, intermediate and dry zones of the country. World-wide, this crop is reported to be infected by different species of begomovirus and cause significant yield reduction. In Sri Lanka, yellow vein mosaic disease (YVMD) is considered as an unmanageable wide-spread disease in okra cultivation [7]. A very few studies, such as determination of disease incidence [8], attempt to detect the associated pathogen based on partial amplification of virus DNA [9] and screening of resistant okra varieties [10] have been done on this aspect in Sri Lanka. 
However, detailed molecular characterization of Sri Lankan biotypes of the begomovirus causing okra yellow vein mosaic disease (OYVMD) has not been studied yet. Therefore, the present study attempted to identify and characterize begomovirus species associated with OYVMD.

\section{Materials and Methods \\ Sampling and DNA extraction}

Leaf samples of healthy okra plants and okra plants showing yellow vein mosaic symptoms only were collected from six different locations (i.e. Jaffna, Vavuniya, Kandy, Matara, Trincomalee and Puttalam) across Sri Lanka between May and July in 2015. In each location, leaf samples were collected from three different farmer's field when the plants were at their post-flowering stage. Total DNA was extracted according to the method described by Jeyaseelan et al. [11].

\section{PCR amplification, cloning and sequencing}

Initially, the presence of begomovirus in the DNA samples was confirmed by amplifying partial genome of begomovirus DNA-A using a pair of degenerate primers [12]. Later, the full-length genome of DNA-A was amplified using three sets of degenerates overlapping primers (OY2395F / OY680R, MKBEGF4 / MKBEGR5 and GEMA1223F / GEMA2454R) as explained by Venkataravanappa et al. [13]. These primers were designed with approximately 200 bp length of sequence overlapping between the segments in order to get the whole coverage of full genome. The PCR reactions were done in a Veriti® 96 well Thermal cycler (Applied Biosystem, USA), using commercially available PCR mix (PCR Biosystem, UK). The PCR conditions were maintained as an initial denaturation at $94{ }^{\circ} \mathrm{C}$ for $3 \mathrm{~min}$, followed by 35 cycles of denaturation at $94{ }^{\circ} \mathrm{C}$ for 1 min, annealing temperature at $60{ }^{\circ} \mathrm{C}$ for $45 \mathrm{~s}$ and extension at $72{ }^{\circ} \mathrm{C}$ for $1 \mathrm{~min}$ with a final extension for $10 \mathrm{~min}$ at $72{ }^{\circ} \mathrm{C}$. Similarly, attempts were made to amplify DNA-B and betasatellite as described by Rojas et al. [14] and Jeyaseelan et al. [11] respectively. The PCR products were purified using a spin column purification kit (NBS biological Ltd, Huntingdon, UK) and cloned into $\mathrm{pCR}^{\circledR} 2.1$ vector using a TA cloning kits (Invitrogen, USA) according to the manufacturers' guidelines. The clones were sequenced separately by automated sanger sequencing service (Source Bioscience, UK) using M13 forward and reverse primers.

\section{Sequence analysis}


The three overlapping partial DNA-A sequences were assembled and the complete genome of each isolate was prepared. The sequences were initially identified using the BLAST $n$ program available at National Center for Biotechnology Information (NCBI) (https://blast.ncbi.nlm.nih.gov/Blast.cgi.). The DNA-A sequences of the present isolates were compared with the sequences of other begomoviruses retrieved from the GenBank database (Table 1). Multiple sequence alignment was done using the Multiple Sequence Comparison by LogExpectation (MUSCLE) tool [15] in MEGA 7.0 software [16]. ORF regions and amino acid sequences of proteins were determined using online tool ExPASy Bioinformatics Resource Portal (https://web.expasy.org/translate/). Pair wise identity scores were generated using Sequence Demarcation Tool (SDT) software [17], and phylogenetic tree was generated using MEGA 7.0 with 1000 bootstrap replications [20].

After complete identification, the nucleotide sequences were deposited in GenBank database (Accession NoKX698087- KX698092 and MH455207- MH455212).

\section{Detection of recombination events}

Possible recombination events were analysed with sequences retrieved from the GenBank database (Table 1). Detection of potential recombinant sequences, likely parental sequences, and recombination breakpoints were carried out using RDP, GENECONV, BootScan, MaxChi, Chimaera, SiScan and 3Seq recombination detection methods as implemented in Recombination Detection Program (RDP) v. 4.0 [18]. The analysis was performed with default settings with a 0.05 P- value cut-off, and standard Bonferroni corrections were used throughout.

\section{Results}

In this study, diseased samples were collected from plants affected by OYVMD. The disease is characterized by alternating green and yellow patches, cleaning of veins and venous chlorosis of leaves only. The initial sample analysis with the pair of degenerate primers [16] yielded a 520 bp PCR product in all symptomatic samples (Supplementary Fig. 1). Similarly, the three sets of primers used to amplify overlapping regions of the DAN-A genome yielded single PCR products in all tested symptomatic samples (Supplementary Fig. 2-4). However, none of the samples showed amplification by the primers specific to DNA-B genome of the begomovirus. However, about $1.3 \mathrm{~KB}$ of PCR product was observed in all symptomatic samples when amplified with the betasatellite specific primers (Supplementary Fig. 5). 


\section{Molecular characterization of DNA-A}

The complete DNA-A genome of 12 begomovirus isolates representing six districts in Sri Lanka were obtained (Table 2). Size of the complete DNA-A genome varied greatly among the isolates and it ranged from $2735 \mathrm{bp}$ to $2786 \mathrm{bp}$. The number of ORF regions predicted in the genome was not equal in all the isolates. There were two distinct groups noticed among the isolates, one group (Tr01, Tr02, Ja01, Va01, Va02, Pu01 and Ma01) had six ORF regions and the other group ( $\mathrm{Ja02}, \mathrm{Pu} 02, \mathrm{Ma02}, \mathrm{Ka01}$ and $\mathrm{Ka} 02)$ had seven ORF regions. In isolates with six ORF regions, two of them were located in the sense strand and four were in the antisense strand. The sequences of two ORF regions in the sense strand showed higher similarity with begomovirus $A V 1$ and $A V 2$ genes. The four ORF regions in the antisense strand were similar to $A C 1, A C 2, A C 3$ and $A C 4$ genes present in begomovirus. The isolates with seven ORF regions in their DNA-A had an additional gene, AC5 in the antisense strand.

Genome of all the isolates (Table 2) had an intergenic region (IR) between the upstream of ORF coding for AC1 protein and upstream of ORF coding for AV2 protein. The IR of isolates having seven ORF regions consisted 316 nucleotides, but the isolates having six ORF regions had IR with 267 nucleotides. The IR of the isolates in both groups showed several features specific to begomoviruses. A TATA box was detected in each of the isolates at 5' region (Supplementary Fig. 6). There was a highly conserved region nearly in the middle of IR. The conserved region consisted a stem and loop structure, and the loop made by nonanucleotide sequence (TAATATTAC).

The BLASTn analysis revealed that the isolate Tr01, Ja01, Va01, Va02, Pu01 and Ma01 has nucleotide sequence which have $98 \%$ sequence identity with Okra enation leaf curl virus (OELCuV) [India: Tamil Nadu: Theni: 2014] isolate but the isolate Tr02 showed maximum 96\% sequence identity with the same isolate. The rest of the isolates showed their highest identity with different begomovirus isolates reported from okra in various regions in India. The isolate $\mathrm{Ja} 02, \mathrm{Pu} 02$ and $\mathrm{Ma} 02$ showed their highest identity, 97\%, 96\% and $98 \%$ respectively, with Bhendi yellow vein India virus (BYVIV) [India:Jalgov:OY124:2006]. The isolate Ka01and $\mathrm{Ka} 02$ showed their highest identity (99\%) with Bhendi yellow vein mosaic virus (BYVMV) [India:Tirupathi:OY99:2005] and BYVMV [India:Raichur:OY54B:2005] respectively.

Pairwise sequence analysis with sequence demarcation tool (SDT) revealed that nucleotide sequences of isolates Ja01, Ma01, Tr01, Va01, Pu01, Tr02 and Va02 had $98.9 \%$ to $99.9 \%$ sequence identity with each other (Supplementary Fig. 7). At the same time, they showed $80.9 \%$ to $88.9 \%$ identity with rest of the five isolates. 
Among the rest of the five isolates, the isolates $\mathrm{Ka} 01$ and $\mathrm{Ka} 02$ showed $99.2 \%$ identity between them, however, they showed $89.7 \%$ to $90.2 \%$ identity with $\mathrm{Ja} 02$, Ma02 and Pu02. The isolates Ja02, Ma02 and Pu02 showed $95.2 \%$ to $96.8 \%$ identity among them. According to ICTV species demarcation threshold, an isolate with $<91 \%$ of sequence identity will be considered as distinct species [19]. Therefore, the results of SDT analysis showed that three different species of begomovirus are associated with OYVMD in Sri Lanka.

Further comparisons were made using SDT with different species of begomoviruses (according to recent updates of ICTV species list on March, 2019) associated with diseases in okra (Fig. 7). Isolates Ja01, Ma01, Tr01, Va01, Pu01, Tr02 and Va02 showed maximum identity (from 91.9\% to 92.3\%) with OELCuV [IN:SonEL10:06]. Pairwise identity score against various isolates of species BYVMV and showed $79.8 \%$ to $87.3 \%$ identity. Analysis with other selected isolates showed $68.8 \%$ to $79.2 \%$ identity. Based on these observations, Isolates Ja01, Ma01, Tr01, Va01, Pu01, Tr02 and Va02 were considered as different isolates of OELCuV.

The isolates $\mathrm{Ka} 01$ and $\mathrm{Ka} 02$ showed highest sequence identity with various BYVMV isolates listed by ICTV and the percentage of identity was between $92.7 \%$ to $98.7 \%$. The percentage of identity with rest of the okra associated isolates, including a BYVMV isolate BYVMV[IN:Mah:NOL751:08], ranged from 69.5\% to $87.7 \%$. As the isolates $\mathrm{Ka} 01$ and $\mathrm{Ka} 02$ show highest identity with species BYVMV and as the identity is greater than 91\%, these two isolates were considered as isolates of BYVMV (Fig. 1).

The isolates Ja02, Ma02 and Pu02 showed highest sequence identity, 92.2\%, 93.0\% and 91.6\% respectively, with two BYVMV isolates BYVMV[IN:Coi:OYCO4:04] and BYVMV[IN:Mah:NOL751:08]. The percentage of identity with all other isolates of BYVMV and other begomovirus species associated with okra ranged from $68.6 \%$ to $90.8 \%$. According to ICTV regulations, the isolates $\mathrm{Ja} 02$, Ma02 and $\mathrm{Pu} 02$ were also classified as isolates of species BYVMV (Fig. 1).

In overall, the 12 isolates sequenced in this study consisted of two different begomovirus species, namely BYVMV and OELCuV. As the sequence identity threshold level for differentiation of strains of a species is $<94 \%$ [23], it is evident that there are two different strains of BYVMV associated with OYVMD samples (strain one from Ka01 and $\mathrm{Ka02}$ samples and strain two from Ja02, Ma02 and Pu02 samples) used for the present study. 


\section{Phylogenetic analysis}

The phylogenetic analysis carried out with DNA-A genome of selected begomoviruses revealed that the virus species OELCuV, Bhendi yellow vein Bhubhaneswar virus (BYVBhV), Bhendi yellow vein Haryana virus (BYVHV) and BYVMV might arose from a common ancestor, with 93\% bootstrap percentage. All the Sri Lankan BYVMV isolates clustered with BYVMV isolates reported from different parts of India.

On the other hand, all Sri Lankan OELCuV isolates, the OELCuV isolate [India:Sonipat EL10:2006] reported from India and the BYVBhV isolate [India:Orissa:OYBH:2003] reported from India might arose from a common ancestor (with $79 \%$ bootstrap percentage). All Sri Lankan OELCuV isolates clustered with the OELCuV isolate [India:Sonipat EL10:2006], with 96\% bootstrap percentage (Fig. 2).

Recombination analysis showed the presence of recombinant fragments in the virus isolates associated with okra in Sri Lanka. The recombinants formed by the exchange of genomes of begomoviruses reported from India and Sri Lanka. The recombination events were detected in isolates of BYVMV[LK:Jaf:Ja02:15], OELCuV[Lk:Tri:Tr01:15], BYVMV[LK:Put:Pu02:15] and BYVMV[LK:Mat:Ma02:15] (Table 3).

The recombinant BYVMV[LK:Jaf:Ja02:15] formed by the exchange of 444 nucleotides between major parent BYVMV[IN:Mah:NOL751:08] and minor parent BYVMV[IN:Har:07]. The recombination event was detected in seven different methods (RDP, GENECONV, BootScan, MaxChi, Chimaera, SiScan and 3Seq) of analysis, and $2.1 \times 10^{-17}$ was the maximum significant value obtained in RDP method. The exchanged segment covers complete nucleotide sequence of $A C 2$ gene and portions of $A C 1$ and $A C 3$ genes.

The isolate OELCuV[Lk:Tri:Tr01:15] showed a recombination event at nucleotide position $90 \mathrm{bp}-1162 \mathrm{bp}$ with BYVMV[LK:Jaf:Ja02:15] and OELCuV[IN:SonEL10:06] as major and minor parents, respectively. The recombination event was detected in seven different methods of analysis with $1.89 \times 10^{-39}$ as the maximum significant value. The exchanged segment covers complete nucleotide sequence of $A V 1$ and $A V 2$ genes.

Two recombination events were detected in isolate BYVMV[LK:Put:Pu02:15]. The first event was between the 2375 - 2465 bp position (OELCuV[LK:Vav:Va02:15] major parent BYVMV[LK:Kan:Ka01:15] minor parent). The second event was between 102 - 550 bp position (the major parent OELCuV[IN:SonEL10:06] and minor parent BYVMV[IN:Har:07]).

In isolate BYVMV[LK:Mat:Ma02:15] two more recombination events were detected in DNA segments 464 $1027 \mathrm{bp}$ and 116 - $2486 \mathrm{bp}$. In the first recombination event major and minor parents were BYVMV[IN:Har:07] 
and BYVMV[LK:Jaf:Ja02:15] respectively. The recombination event was detected in seven different methods of analysis with $3.45 \times 10^{-10}$ as the maximum significant value. The exchanged segment covers complete nucleotide sequence of $A C 5$ gene and portion of $A V 1$ and $A V 2$ genes. In the second recombination, BYVMV[IN:Coi:OYCO4:04] and OELCuV[Lk:Tri:Tr01:15] were major and minor parents respectively. The recombination event was detected in six different methods of analysis with $4.42 \times 10^{-14}$ as the maximum significant value. The exchanged segment covers complete nucleotide sequence of $A C 2$ and $A C 4$ genes and portion of $A C 3$ and $A C 1$ gene.

\section{Discussion}

The information on molecular characterization of the viral strains will help in developing management strategies to control plant diseases. In present study, the begomoviruses associated with yellow vein mosaic disease in okra plants in Sri Lanka were identified based on sequencing of viral genome. The sequences reported in this study are the first complete begomovirus genome sequences of OYVMD causing agents in Sri Lanka. According to recent ICTV report only four begomovirus species has been associated with okra in Indian subcontinent; the species BYVBhV, BYVMV, BYVHV and OELCuV.

In the present study, the isolates can be grouped into three, based on the ICTV criteria for pairwise sequence identity $(<91 \%)$; isolates $\operatorname{Tr} 01, \mathrm{Tr} 02, \mathrm{Ja} 01, \mathrm{Ma} 01, \mathrm{Pu} 01, \mathrm{Va} 01$ and $\mathrm{Va} 02$ were in group one, isolates $\mathrm{Ka} 01$ and $\mathrm{Ka} 02$ were in second group and the isolates $\mathrm{Ja} 02, \mathrm{Ma} 02$ and $\mathrm{Pu} 02$ were in the third group. However, SDT pairwise analysis with okra infecting begomoviruses sequences listed in ICTV showed different results. The isolates in group two and three showed $>91 \%$ sequence identity with BYVMV isolates and the first group showed highest similarity with OELCuV. Therefore, ultimately it was concluded that the OYVMD in Sri Lanka is caused by two different species of begomovirus. Even though, the isolates Ja02, Ma02, Pu02, Ka01 and Ka02 were named as $\mathrm{BYVMV}$, isolates $\mathrm{Ka} 01$ and $\mathrm{Ka} 02$ showed significant variation from other three isolates. Therefore, these two groups are two different strains of BYVMV.

The isolates Tr01, Tr02, Ja01, Ma01, Pu01, Va01 and Va02 were named as OELCuV according to the ICTV criteria, however, they showed a marginal sequence identity (ranged from 91.9\% to 92.3\%) with the OELCuV [IN:SonEL10:06], the isolate listed in ICTV begomovirus list.

Moreover, all the OYVM disease samples gave positive amplification to the Bhendi yellow vein mosaic betasatellite (BYVMB) with about 1300 bp length which we have reported recently [7]. Therefore, in the 
present study, the DNA samples of OYVM diseased plants had DNA-A component and betasatellite, but not DNA-B component. This clearly shows that the begomoviruses that causing OYVMD in Sri Lanka is a monopartite begomovirus.

In general, begomoviruses are more vulnerable to recombination. The tendency of begomoviruses to evolve by recombination and component exchange is likely to play a major part in their diversity and host range [20]. Present study has elucidated putative recombination events in Sri Lankan OELCuV isolate Tr01. The putative parents of the recombination event include isolates of BYVMV[LK:Jaf:Ja02:15] and OELCuV[IN:SonEL10:06]. Molecular characterization of OELCuV associated with okra was first done by Venkataravanappa et al. [21] in India. In that study they found similar observation that the OELCuV isolate raised from recombination in three putative parents, namely Cotton leaf curl Bangalore virus (CLCuBaV), Mesta yellow vein mosaic virus (MeYVMV) and BYVMV. In the present study it has been also noticed that the Sri Lankan BYVMV isolate Pu02 and Ma02 might arise from a recombination between BYVMV and OELCuV.

\section{Conclusion}

Based on the findings of molecular identification and characterization it can be concluded that okra yellow vein mosaic disease (OYVMD) in Sri Lanka is caused by monopartite begomoviruses. There are two distinct monopartite begomoviruses, Okra enation leaf curl virus (OELCuV) or Bhendi yellow vein mosaic virus (BYVMV) associated with Bhendi yellow vein mosaic betasatellite (BYVMB) present in OYVMD samples collected from Sri Lanka. This is the first detailed study of complete nucleotide sequences of begomoviruses associated with okra yellow vein mosaic disease.

\section{References:}

1. Kamaal N, Akram M, Pratap A, Yadav P (2013) Characterization of a new begomovirus and a beta satellite associated with the leaf curl disease of French bean in northern India. Virus Genes 46:120-127. https://doi.org/10.1007/s11262-012-0832-8

2. Briddon RW, Patil BL, Bagewadi B, Rehman MSN, Fauquet CM (2010) Distinct evolutionary histories of the DNA-A and DNA-B components of bipartite begomoviruses. BMC Evolutionary Biology 97: 117.

3. Hu T, Song Y, Wang Y, Zhou X (2020) Functional analysis of a novel $\beta$ V1 gene identified in a 
geminivirus betasatellite. Sci. China Life Sci. 63: 688-696. https://doi.org/10.1007/s11427-020-1654-x

4. Singh AK, Chattopadhyay B, Chakraborty S (2012) Biology and interactions of two distinct monopartite begomoviruses and betasatellites associated with radish leaf curl disease in India. Virol J 9:1-18

5. Nawaz-ul-rehman MS, Fauquet CM (2009) Evolution of geminiviruses and their satellites. FEBS Lett 583:1825-1832. https://doi.org/10.1016/j.febslet.2009.05.045

6. Kumar J, Kumar J, Singh SP, Tuli R (2014) Association of Satellites with a Mastrevirus in Natural Infection: Complexity of Wheat Dwarf India Virus Disease. Journal of Virology 88:7093-7104. http://dx.doi.org/10.1128/JVI.02911-13.

7. Jeyaseelan TC, Jeyaseelan EC, Costa DM De, Shaw MW (2018) Molecular characterization and phylogenetic analysis of betasatellite molecules associated with okra yellow vein mosaic disease in Sri Lanka. Trop Plant Pathol 43:468-472.

8. Deepal P, Wasala S, MCM Z, Wijayaratne L (2014) Characterization of yellow vein mosaic virual disease in Okra (Abelmoschus esculentus). plant Sci 6th Annu Symp 66

9. Senevirathna HMSI, Wasala SK, Senanayake DMJB, Weerasekara D (2016) Characterization and Detection of Yellow Vein Disease of Okra ( Abelmoschus esculentus ( L .) Moench ) in Sri Lanka. Trop Agric Res 27:360-369

10. Samarajeewa P, Rathnayaka R (2004) Disease resistance and genetic variation of wild relatives of okra (Abelmoschus esculentus L.). Ann Sri Lanka Dep Agric 6:167-176

11. Jeyaseelan TC, Jeyaseelan EC, Costa DM De, Shaw MW (2019) Selecting and optimizing a reliable DNA extraction method for isolating viral DNA in okra (Abelmoschus esculentus). 14:

12. Deng D, Mcgrath PF, Robinson DJ, Harrison BD (1994) Detection and differentiation of whiteflytransmitted geminiviruses in plants and vector insects by the polymerase chain reaction with degenerate primers. Ann.applBiol 125:327-336

13. Venkataravanappa V, Reddy LCN, Jalali S, Reddy KM (2012) Molecular characterization of distinct bipartite begomovirus infecting bhendi (Abelmoschus esculentus L .) in India. Virus Genes 44:522-535. https://doi.org/10.1007/s11262-012-0732-y

14. Rojas MR, Gilbertson RL, Russel DR, Maxwell DP (1993) Use of Degenerate Primers in the Polymerase Chain Reaction to Detect Whitefly-Transmitted Geminiviruses. Plant Dis 77:340-347

15. Edgar RC (2004) MUSCLE : multiple sequence alignment with high accuracy and high throughput. 
Nucleic Acids Res 32:1792-1797. https://doi.org/10.1093/nar/gkh340

16. Kumar S, Stecher G, Tamura K (2016) MEGA7 : Molecular evolutionary genetics analysis version 7 . 0 for bigger datasets. Mol Biol Evol 33:1870-1874

17. Muhire BM, Varsani A, Martin DP (2014) SDT : A virus classification tool based on pairwise sequence alignment and identity calculation. PLoS One 9:1-8. https://doi.org/10.1371/journal.pone.0108277

18. Martin DP, Murrell B, Golden M et al (2015) RDP4 : Detection and analysis of recombination patterns in virus genomes. Virus Evol 1:1-5. https://doi.org/10.1093/ve/vev003

19. Brown JK, Zerbini FM, Navas-Castillo J et al (2015) Revision of Begomovirus taxonomy based on pairwise sequence comparisons. Arch Virol 160:1593-1619. https://doi.org/10.1007/s00705-015-2398-y

20. Seal SE, VandenBosch F, Jeger MJ (2006) Factors influencing begomovirus evolution and their increasing global significance : Implications for Sustainable Control. CRC Crit Rev Plant Sci 25:23-46. https://doi.org/10.1080/07352680500365257

21. Venkataravanappa V, Reddy CNL, Jalali S et al (2015) Molecular identification and biological characterisation of a begomovirus associated with okra enation leaf curl disease in India. Eur J Plant Pathol 141:217-235. https://doi.org/10.1007/s10658-014-0463-0 
Fig. 1 Pairwise identity score generated from DNA-A nucleotide sequences of different begomovirus isolates associated with various virus diseases in okra.

Fig. 2 Phylogenetic tree of begomovirus associated with okra. Phylogenetic dendrograms based upon alignments of the complete nucleotide sequences of the DNA-A of selected sequences. Sri Lankan Okra enation leaf curl virus (OELCuV) is coloured red and Bhendi yellow vein mosaic virus (BYVMV) is coloured blue. Other begomoviruses associated with okra are coloured black. Horizontal distances are proportional to mutation distances whereas vertical distances are arbitrary. The numbers at each branch indicate percentage bootstrap confidence scores (1000 replicates). 